\title{
THE LEGAL AND ECONOMIC VALUE OF INTELLECTUAL PROPERTY (IP)
}

\author{
Massimo Barbieri ${ }^{1}$ \\ ${ }^{1}$ Politecnico di Milano (Technology Transfer Office) Piazza L. da Vinci
}

December 7, 2020

\begin{abstract}
The identification of the closest prior art is a good starting point for evaluating the legal and the economic value of an intellectual property (IP) asset. The next step is the evaluation of the patentability requirements (novelty, inventive step and industrial application).

Other factors to be taken into consideration are: potential market, development stage, time to market, product lifecycle, technology risk, detectability, design arounds and product value.

License agreements are the best way to ascribe value to an academic invention.
\end{abstract}

\section{Introduction}

The evaluation of a new invention is a very difficult task, because sometimes the Technology Transfer (TT) managers do not have all the information necessary.

Having a complete description of an invention is a good starting point but sometimes it is not enough.

It is of paramount importance to understand the technical problem solved by an invention, and to know if and how someone else has already solved the same problem and the closest prior art.

Furthermore, it is useful to highlight the essential technical features of the invention: this is a good starting point to carry out a comprehensive state-of-the-art search in patent databases.

After having identified the closest prior art (one or two documents), the next step is the evaluation of the patentability requirements.

\section{Patentability requirements}

The patentability requirements of an invention are summarized in Table 1.

\begin{tabular}{ll}
\hline Novelty (art. $54-\mathrm{EPC})$ & $\begin{array}{l}\text { An invention is considered to be new if it does not } \\
\text { form part of the state of the art. }\end{array}$ \\
\hline Inventive step (art. $56 \mathrm{EPC})$ & $\begin{array}{l}\text { An invention is considered as involving an inventive } \\
\text { step if, having regard to the state of the art, it is } \\
\text { not obvious to a person skilled in the art. } \\
\text { An invention is considered as susceptible to an } \\
\text { industrial application if it can be made or used in } \\
\text { any kind of industry, including agriculture. }\end{array}$ \\
\hline
\end{tabular}


Table 1 - List of patentability requirements

The novelty requirement is simple to explain and to evaluate: an invention is new when it differs from the prior art. Not much difference is required; a simple difference is sufficient. [1]

The inventive step is more subjective but the Problem and Solution Approach (PSA), provided by the EPO, can help to complete this task.

The first step is to establish the differences between the invention and the prior art. Then, given those differences, one should ask: would an ordinary skilled technician have been motivated to modify or combine teachings of the prior art in a manner that would arrive at the claimed invention? If the answer is yes, then the technical solution is considered to be obvious in the light of prior art and it is not an inventive step.

The inventive step hurdle can be easily explained with an example.

Suppose we evaluate an invention which claims an alloy composition ABC for use as a corrosion-resistant material in devices exposed to saline environments.

Two documents (D1 and D2) constitute the prior art.

Document D1 describes an alloy ABD having good corrosion resistance (without specifying that it functions in saline environments). The difference is the substitution of $\mathrm{C}$ with $\mathrm{D}$ in the alloy.

Document D2 discloses a composition suitable for use in the manufacture of boat hulls and comprising B alloyed with $\mathrm{C}, \mathrm{D}$ or $\mathrm{E}$.

D2 teaches that the elements $\mathrm{C}$ and $\mathrm{D}$ may be mixed with $\mathrm{AB}$, whereas $\mathrm{C}, \mathrm{D}$ and $\mathrm{E}$ are elements which may be interchanged with $\mathrm{B}$.

Therefore, a person skilled in the art would be motivated to replace element D with $\mathrm{C}$ or $\mathrm{E}$ to obtain a good resistance to corrosion in a saline environment. [3]

Factors other than the patentability requirements

Other factors to be taken into consideration are listed in Table 2.

Market

Development stages

Time to market

Product lifecycle

Technology risk
First evaluate the size and growth of the market, considering all possible applications of the invention

The development stages are the following: conceptual stage, experimental stage, simulation of the op This is the time required, starting from the actual development stage of the invention to the launch $c$ This refers to the lifetime of the product on the market or, in other words, the time in which it rema Some inventions are based on a well-established technology, that makes the products well accepted by

Table 2 - List of other factors than the patentability requirements

Detectability, design arounds and product value are other factors to consider.

\section{The economic evaluation of an early-stage invention}

Evaluating an early-stage invention is really a challenging task.

While cost, Market, and Discounted Cash Flow (DCF) methods are usually used in the economic evaluation of patented products, they are not suitable to estimate the value of a new technology or an early-stage invention.

Real Options methods (compound options, hybrid real options) or a combination with other methods (Fuzzy Set Theory, Scenario Planning, Analytic Hierarchy Process or Game Theory) could be a better solution. [4]

\section{Procedure adopted by Politecnico di Milano}

Politecnico di Milano has developed a policy in order to better manage the evaluation and protection process. 
The "Invention process" is characterized mainly by the following steps:

- completion of the "Disclosure Form"

- evaluation of patentability requirements and the potential commercial value

- filing of the patent application

- identification of potential licensees

- negotiation of a licensing agreement

One of the most important steps in the "Invention Process" is the drafting of a document (Invention and Technology Disclosure form), which essentially has a dual purpose:

it contains a detailed description of the invention.

it constitutes a declaration of the inventors to transfer the ownership to the University.

The detailed description of the invention allows the Technology Transfer Office (TTO) staff to conduct an effective novelty search.

TTO staff evaluate the content of the Disclosure Form.

The criteria applied by TTO include:

- the technical feasibility of the invention.

- the patentability requirements.

- the assessment of a good probability that the invention can be transferred to industry.

If the response is negative, the ownership (the patrimonial rights) will be given back to inventors.

If the response is positive, a national patent application will be filed as a priority application.

TTO staff will select a patent attorney who will be responsible for drafting the patent application. The TTO staff will send the patent attorney a detailed description of the invention, with a list of the closest prior art documents.

The priority application will be filed in Italy (Italian mandatory law).

Typically, TTO implements a strategy based on a national first filing, which establishes a priority date.

An application may be filed at one of the 103 Chambers of Commerce or directly at the Italian Patent and Trademark Office (UIBM). An e-filing procedure is also available.

Under the current rules an application is kept under secrecy for military purposes for a maximum of 90 days, after which it can be disclosed to the public if advanced accessibility has been requested by the applicant, otherwise it is available after 18 months, as per usual.

The EPO carries out a search report for Italian patent applications filed from $1^{\text {st }}$ July 2008.

The application is sent to the EPO together with a translation of the claims in

English (provided by the applicant himself or made by the EPO at an official fee

of \euro 200, within 4 months of the filing date.

The EPO will send the UIBM a search report with a preliminary patentability opinion within 9 months from the filing date to allow the applicant to decide whether or not to proceed with a European Patent (EP) or any other foreign extensions.

After the national filing there is one year to decide whether or not to extend the patent.

During this year the TTO staff will proceed with finding companies potentially interested in the patent. This phase requires working closely with the inventor.

License agreements are the best way to ascribe value to an academic invention. 
After an industrial property title has been filed or registered, the next question is how to exploit the invention.

For a company, there are two main options: a) implementation by the company itself, and b) sale, licensing or cross-licensing entrusted to third parties.

By contrast, universities have a rather restricted scope of action. They are not allowed to market inventions directly (except through a spin-off) and must therefore identify a company on the market to negotiate either a license agreement for the use of the patent (either exclusive or non-exclusive) or an assignment agreement, which is basically an outright transfer.

A license agreement, which may relate to either patents or know-how or both, is an atypical (free form) agreement and has some limitations, such as:

1. the territorial scope: the holder has no exclusivity (the invention can be freely implemented) outside the borders of the states in which the exclusive rights title has been validated.

2. the time scope: the duration of protection is limited (twenty years from when the patent application is filed) and affects the duration of the agreement.

3. the scope resulting from the right of use: scope of coverage determined by the contents of the claims.

4. the market sector or field of use.

During negotiations, the potential licensee must check carefully:

* the ownership of industrial property rights

* the legal status

* the validity of the titles

* the time to market

* the estimation of the fields of use and of the markets

* the freedom to operate

The agreement may provide for:

* a license on later improvements

* a collaboration to facilitate the implementation of the invention operation

* any sub-licenses

The costs of maintenance of industrial property rights are usually borne by the licensee.

Other useful tools during negotiations are the following: confidentiality agreements, letters of intent, and joint development agreements.

The only guarantee that the licensor takes on is the one relating to ownership, whereas guarantees are expressly excluded from agreements with regard to:

* the validity of industrial property titles

* the patentability of the inventions

* the presence of infringements

Payment is generally in monetary form [reimbursement for the achievement of the titles; assumption of future maintenance costs; payment of a fixed sum as a down payment/lump sum, possibly divided into several instalments or royalties, usually calculated as a percentage of sales turnover (or periodic fees)], but it can also be non-monetary [cross-licensing, contributions in kind (e.g., equipment, research contracts)]. [2] 
Within one year from the filing date, it is necessary to decide whether the patent should be extended or not at an international level.

PCT is basically an option for future patenting, that provides the applicant with a further delay before deciding whether or not to apply.

The PCT process provides the advantage of a longer investigation of the technological potential of the invention, and in case of a negative assessment, the application can be withdrawn before entering into expensive national or regional phases.

\section{Final remarks}

The economic evaluation of a new technology is only a small part of the entire technology transfer process.

Usually information made available in a "Disclosure Form" is sufficient to give a perceived value, but not a quantitative one.

Determining value for early-stage inventions is not part of the licensing process, because the involvement of the scientist would be essential and because inventor contacts are crucial for marketing the invention. [5]

\section{References}

[1] Franzosi, Mario, Novelty and Non-Obviousness. The Relevant Prior Art, The Journal of World Intellectual Property, Vol 3, Issue 5, p. 683https://doi.org/10.1111/j.1747-1796.2000.tb00148.x

[2] Barbieri, Massimo, Innovation and Industrial Property Rights (September 10, 2017). Chapter in book: "Developing Biomedical Devices" (2014), Available at SSRN:https://ssrn.com/abstract=3034950

[3]Davidson, Kristi, The Non-Obviousness Hurdle, Heat Treating Progress, July/August 2009, p. 7, Available at:https://www.asminternational.org/web/hts/heat-treating-progress-magazine-archives/-/journal_content/56/10192/HTP00904P07/PERIODICAL-ARTICLE?doAsUserId=vzMatAB\%252FAxI\%253D

[4]Lou, Yan, Zhang, Hong, Huang, Lucheng, Review on methods of new technology valuation, 2010 International Conference on E-Business and E-Government, Guangzhou, 2010, pp. 1932-1935, DOI 10.1109/ICEE.2010.4888, Available for free athttps://www.researchgate.net/publication/252043718_Early_phase_technology_management_valuation_practices_by_university_licensing_offices_in_the_United_States_Empirical_data_from_a_survey_of_the_top_100_organizations

[5] Hallam R.A., Cory, Leffel, Anita, Chinea, Ismael, Early Phase Technology Management Valuation Practices by University Licensing Offices in the United States: Empirical data from a Survey of the Top 100 Organizations, 2011 Proceedings of PICMET '11: Technology Management in the Energy Smart World (PICMET), Portland, OR, 2011, pp. 1-11. 